\title{
Sports Medicine Specialization Theses: Bibliometric Analysis of the Last 15 Years in Turkey
}

\author{
Spor Hekimliği Uzmanlık Tezleri: Türkiye'de Son 15 Yılın Bibliyometrik \\ Analizi *
}

\author{
Sabriye Ercan
}

Sports Medicine Department, Faculty of Medicine, Süleyman Demirel University, Isparta, Turkey

\section{S. Ercan (i) \\ 0000-0001-9500-698X}

Geliş Tarihi/Date Received: 29.03.2019

Kabul Tarihi/Date Accepted: 14.05.2019

Yayın Tarihi/Published Online: 01.10.2019

Yazışma Adresi /

Corresponding Author:

Sabriye Ercan

Süleyman Demirel Üniveristesi, Tıp Fakültesi , Spor Hekimliği Ana Bilim Dalı, Isparta, Turkey

E-mail:

sabriyeercan@gmail.com

(C2020 Türkiye Spor Hekimleri Derneği. Tüm hakları saklıdır.

\section{ABSTRACT}

Objective: To conduct bibliometric analysis of the theses completed by sports medicine specialists in the last 15 years and to examine the theses' conversion into articles and their contribution to the literature.

Materials and methods: The theses which were completed between 2002-2017 and accessible by open access were obtained from the digital archive of Database of National Thesis Center of the Turkish Council of Higher Education. The publication of the thesis as an article or not has been examined via Google Scholar.

Result: As a result of digital archive investigation 60 theses was reached. $28.3 \%$ ( $n=$ 17 ) of these were completed by female specialists. Ninety percent $(n=54)$ of the theses were designed as human studies, $8.3 \%(n=5)$ as animal experiments and $1.7 \%$ $(n=1)$ as field surveys. The topics related with exercise and sports physiology were $35 \%(n=21)$, sports injuries and sportive rehabilitation $35 \%(n=21)$, chronic diseases and exercise $15 \%(n=9)$, sports cardiology $5 \%(n=3)$. There was no difference in bibliometric data ( $p>0.05$ ) according to the author's gender and academical degrees of supervisors. $48.3 \%(n=29)$ of the theses were published as an article.

Conclusion: The studies about geriatrics and sport, female and sport, disability and sport, team physician, emergencies in sports medicine and organ transplantation have not been selected as a thesis topic yet. There is a need to conduct thesis studies on these topics to produce higher level scientific articles.

Keywords: bibliometric analysis, sports medicine, thesis.

ÖZ

Amaç: Son 15 yılda spor hekimliği uzmanlık alanında tamamlanan tezlerin bibliyometrik analizini yapmak, tezlerin makaleye dönüştürülme ve literatüre katkı düzeylerini incelemektir.

Gereç ve yöntem: 2002-2017 yılları arasında tamamlanan ve açık erişim ile ulaşılabilen tezler Yüksek Öğretim Kurulu Başkanlığı Tez Merkezi'nin dijital arşivinden tarandı. Tezlerin makale olarak yayınlanıp yayınlanmadığı ise 'Google Akademik' arama motoru üzerinden incelendi.

Bulgular: Dijital arşiv taraması sonucunda 60 adet teze ulaşıldı. Bu tezlerin \%28.3 $(n=17)$ 'ü kadın araştırmacı tarafından yapılmıştı. Tezlerin \%90'ı $(n=54)$ insan çalışması, \%8.3'ü $(n=5)$ hayvan deneyi ve \%1.7'si $(n=1)$ saha taraması olarak tasarlanmıştı. Egzersiz ve spor fizyolojisi konusu \%35 $(n=21)$, spor yaralanmaları ve sportif rehabilitasyon konusu \%35 $(n=21)$, kronik hastalıklar ve egzersiz konusu \%15 $(n=9)$, spor kardiyolojisi konusu $\% 5(n=3)$ oranında tercih edilmişti. Bibliyometrik verilerde yazarın cinsiyeti ve danışmanın unvanına göre fark olmadığı görüldü ( $p>0.05)$. Tezlerin \%48.3 ( $n=29$ )'ünün makale olarak yayınlandığı tespit edildi. 
Sonuç: Yaşlılık ve spor, kadın ve spor, engelliler ve spor, takım doktorluğu, spor hekimliğindeki acil durumlar ve organ nakilleri kapsamındaki çalışmalar henüz tez konusu olarak seçilmemiştir. Bu başlıklarda da tez çalışmalarının yürütülmesine ve yüksek kaliteli bilimsel makalelerin üretilmesine ihtiyaç vardır.

Anahtar sözcükler: bibliyometrik analiz, spor hekimliği, tez.

Available at: http://journalofsportsmedicine.org and http://dx.doi.org/10.5152/tjsm.2020.155

Cite this article as: Ercan S. Sports medicine specialization theses: Bibliometric analysis of the last 15 years in Turkey. Turk J Sports Med. 2020;55(1):21-7.

*Bu çalışma, 22-24 Mart 2019 tarihinde Antalya'da düzenlenen 17. Uluslararası Katılımlı Türk Spor Hekimliği Kongresi’ nde sözlü bildiri olarak sunulmuştur.

\section{GíRiş}

Bibliyometrik analizler, bilimsel literatürü 'büyük resmi görerek' veya 'kuş bakışı' değerlendirmek için kullanılan bilimsel yöntemlerdendir $(1,2)$. Bu analiz yönteminde; tüm mikro ve makro yayın modelleri matematiksel ve istatistiksel hesaplamalar yardımıyla nicel yönden değerlendirilmektedir (3). Bu terim, ilk olarak Prichard tarafından 1969 yılında kullanılmaya başlanmıştır (4). Bu analiz yöntemi, bilimsel yayınları ve bilgiyi analiz edebildiği, literatürün izlenmesini kolaylaştırdığı için 1980'den sonra popüler olmuştur (5). Bilgisayar teknolojilerinin gelişimi ve internet kullanımının artması bu yöntemin 2000'li yllardan sonra yaygınlaşmasını sağlamıștır (3).

Bibliyometrik analizlerde, tezlerin diğer bilimsel araştırma türlerinden ayrı incelendiği bilinmektedir. Çünkü bilimsel alan eğilimlerini belirlemek için diğer araştırma türlerinden çok tezlerin analiz edilmesi önemli bir yol olarak görülmektedir (1). Bu analiz tekniği ile alandaki uzmanların en çok incelediği konuların belirlenmesinin yanı sıra ihmal edilen konuların da saptanması mümkün olabilmektedir. Ayrıca bu verilerin sonuçları daha ileri çalışmaların planlanması için yol gösterici olabilmektedir (1). Diğer taraftan ülkemizdeki kurumların araştırma evrimleri belirlenebilirken ülkemizin diğer ülkelerle karşılaştırması da yapılabilmektedir (6).

Spor hekimliği; egzersizi sağlığın korunması ve hastalıkların tedavisi için kullanan İbn-i Sina, Hipokrat, Galen ve Herodicus gibi tıp biliminin öncü isimlerine kadar uzanan çok eski bir uzmanlık dalıdır (7). Fiziksel aktivite azlığının birçok hastalığın morbiditesini ve mortalitesini artırıyor olması bu hastalıklarla mücadelenin yine fiziksel aktivitenin arttırılması ile gerçekleștirilebileceğini göstermektedir (7). Bunun bir yansıması olarak günümüzde başta spor hekimliği olmak üzere hem sporcu sağlığının hem de egzersizin tüm basamaklarında rolü olan uzmanlık branşlarının popülerliği ve etkinliği artmaktadır (7).

Spor hekimliği ülkemizde 1900'lü yılların başında ilk bilimsel ürünlerini vermiş olsa da yeni uzmanlık alanlarındandır ve hala gelișime açıktır. Bu çalışmanın birinci amacı, spor hekimliği uzmanlarının son 15 yılda hangi alanlarda tez çalışması yaptıklarını, görev tanımları içerisinde yer almasına rağmen hangi konularda daha az çalıştıklarını belirlemektir. Çalışmanın ikinci amacı ise tezlerin makaleye dönüşme ve literatüre katkı düzeylerini incelemektir.

\section{GEREÇ VE YÖNTEMLER}

Türkiye Spor Hekimleri Derneği'nin 'Spor Hekimleri Envanteri'nde yer alan hekimlerin tezleri, Yüksek Öğretim Kurulu Başkanlığı Tez Merkezi'nin (https://tez.yok.gov.tr/UlusalTezMerke zi/) dijital arşivinden tarandı. 2002-2017 yılları arasında tamamlanan ve açı erişim ile ulaşılabilen tezler değerlendirmeye alındı.

Tezler; tezin tamamlandığı yıl, tezin yürütüldüğü fakülte, yazarın cinsiyeti, çalışmanın tipi, Tıpta Uzmanlık Kurulu Spor Hekimliği Çekirdek Müfredatı versiyon 2.2'ye göre çalışmanın kapsamı, tez danışmanının akademik unvanı özelliklerine göre incelendi. Tez yürütücüsü olarak çift danışman bulunan tezlerde, unvanı daha yüksek olan öğretim üyesi değerlendirmeye alındı.

Tezlerin makale olarak yayınlanıp yayınlanmadığı Google Akademik (scholar 
google.com.tr) arama motoru üzerinden tarandı. Makale olarak yayınlanmış olan çalışmalar; makalenin yayın dili ve yayınlandığı derginin indeksi yönünden analiz edildi.

Çalışma, 5 Aralık 2018 tarihinde 2018/338 karar numarası ile yerel etik kurul tarafından onayland.

\section{İstatistiksel analiz}

Veriler, NCSS (Number Cruncher Statistical System) 2007 Statistical Software (Utah, USA) paket programı ile analiz edildi. Verilerin değerlendirilmesinde tanımlayıcı istatistiksel yöntem- ler (sıklık ve yüzde dağılımları) kullanıldı. Nitel verilerin karşılaştırmalarında ise ki-kare ve Fisher's gerçeklik testi uygulandı. Sonuçlar, $\mathrm{p}<0.05$ düzeyinde anlamlı olarak kabul edildi.

\section{BULGULAR}

Dijital arşiv taraması sonucunda açık erişim ile ulaşılabilen 60 teze ulaşıldı. Bu tezlerin \%28.3'ü $(n=17) \quad$ kadın, \%71.7'si $\quad(n=43)$ erkek araştırmacılar tarafından tamamlanmıştı. Yıllar içerisinde spor hekimliği uzmanlığı alanında tamamlanan tez sayısının arttığı gözlendi (Grafik 1).

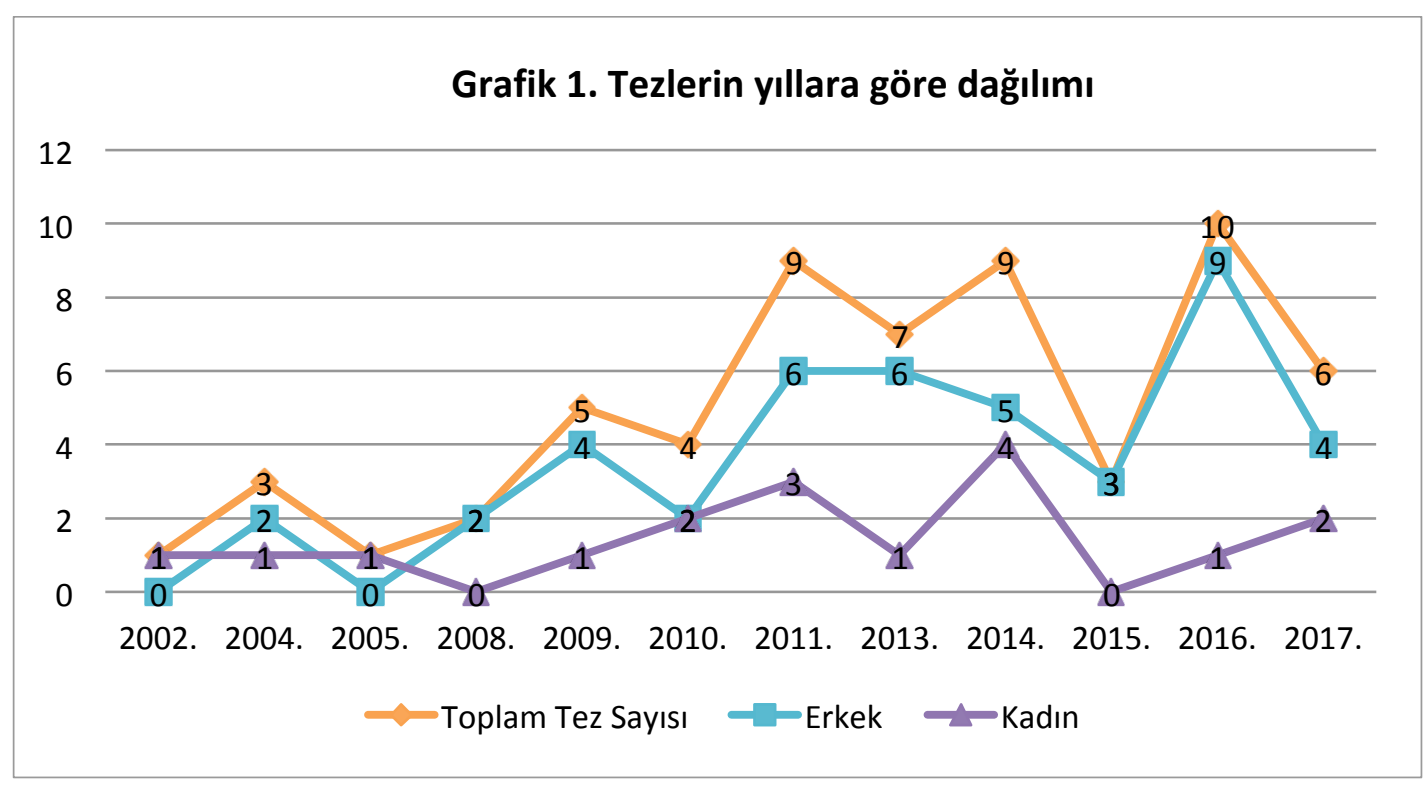

Tamamlanan ve açık erişim ile ulaşılabilen tezlerin \%16.67'si $(\mathrm{n}=10)$ Ankara Üniversitesi'nde, \%16.67'si $(\mathrm{n}=10)$ İstanbul Üniversitesi'nde, \%16.67'si $(\mathrm{n}=10)$ Süleyman Demirel Üniversitesi'nde, \%13.33'ü $(n=8)$ Ege Üniversitesi'nde, $\% 13.33^{\prime} \ddot{\text { u }} \quad(\mathrm{n}=8) \quad$ Uludağ Üniversitesi'nde, \%11.67'si (n=7) Hacettepe Üniversitesi'nde, $\% 10$ 'u $(n=6)$ Gülhane Askeri Tıp Akademisi'nde ve \%1.67'si (n=1) Erciyes Üniversitesi'nde yürütülmüştü.

Tezlerin \%90'ı (n=54) insan çalışması, \%8.3'ü $(n=5)$ hayvan deneyi ve \%1.7'si $(n=1)$ saha taraması olarak tasarlanmıștı. 2002-2013 yılları arasında saha taraması olarak planlanan çalışma bulunmazken tüm zaman dilimlerinde en çok insan çalışmasının tercih edildiği belirlendi (Grafik 2).

Çalışmaların kapsamı, Tıpta Uzmanlık Kurulu Spor Hekimliği Çekirdek Müfredatı versiyon 2.2'ye göre sinıflandırıldığında egzersiz ve spor fizyolojisi konusu \%35 ( $\mathrm{n}=21)$, spor yaralanmaları ve sportif rehabilitasyon konusu \%35 $(n=21)$, kronik hastalıklar ve egzersiz konusu $\% 15(n=9)$, spor kardiyolojisi konusu \%5 ( $n=3)$ oranında tercih edilmiști. Müfredatta yer alan özel gruplarda spor konusu (\%3.3, $\mathrm{n}=2)$ sadece çocuklarda çalışılmıştı. Genel spor hekimliği konusundaki çalışmalar ise radyoloji $(\% 3.3, \mathrm{n}=2)$ ve tıbbi genetik $(\% 3.3, n=2)$ dallarıly birlikte yürütülmüştü (Grafik 3). 

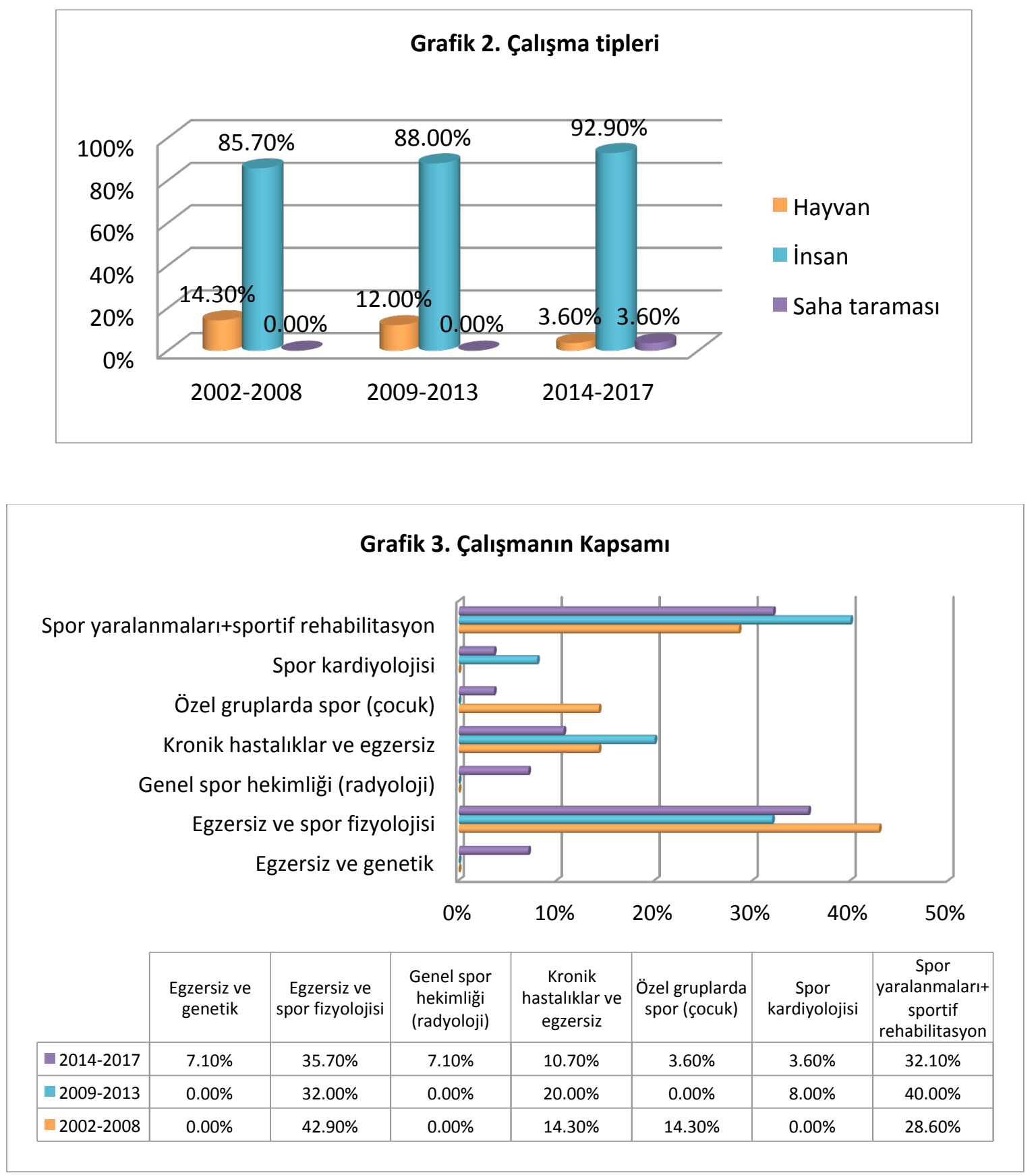

Yazarının cinsiyetine göre; çalıșmanın tamamlandığ ${ }_{1}$ yılların dağılımı $(\mathrm{p}=0.64)$, çalışma tipi $(p=0.74)$, çalışma kapsamı ( $p>0.05)$, danışman unvanı $(p=0.64)$ ve tezin yürütüldüğü fakülte bilgisi $(p=0.6)$ fark oluşturmadı. Danışman un- vanına göre; çalışmanın tipi $(p=0.61)$, çalışmanın kapsamı ( $p>0.05)$ ve tezin yürütüldüğü fakülte bilgisi $(p=0.6)$ fark oluşturmadı. 'Prof. Dr.' ünvanlı danışmanlar 2009-2017 yılları arasında 'Yrd. Doç. Dr. ve Doç. Dr.' ünvanlı 
danışmanlardan daha fazla çalıșma yürütmüștü $(\mathrm{p}=0.04)$.

Tamamlanan ve açık erişim ile ulaşılabilen tezlerin ( $n=60) \quad \% 48.3$ 'ünün $(n=29 ; 2002-2009$ yılları arasında \%41.7, n=5; 2010-2017 yılları arasında $\% 50, \mathrm{n}=24$ ) makale olarak yayınlandığ 1 saptandı. 2010 yılından sonra tamamlanan tezlerin oransal olarak makaleye daha fazla dönüştügü görülse de de bu durum istatistiksel fark oluşturmadı $\quad(\mathrm{p}=0.75) . \quad 2002-2009$ yılları arasında makale yayın dili olarak \%60 $(n=3)$ oranında Türkçe kullanılırken, 2010-2017 yılları arasında yayınların \%75'i (n=18) İngilizce idi $(\mathrm{p}=0.3) .2010$ yilından sonra yayınlanan çalışmaların uluslararası literatüre olan katkısı istatistiksel anlamlı fark oluşturmamakla birlikte daha yüksekti ( $\mathrm{p}=0.1)$, (Grafik 4).

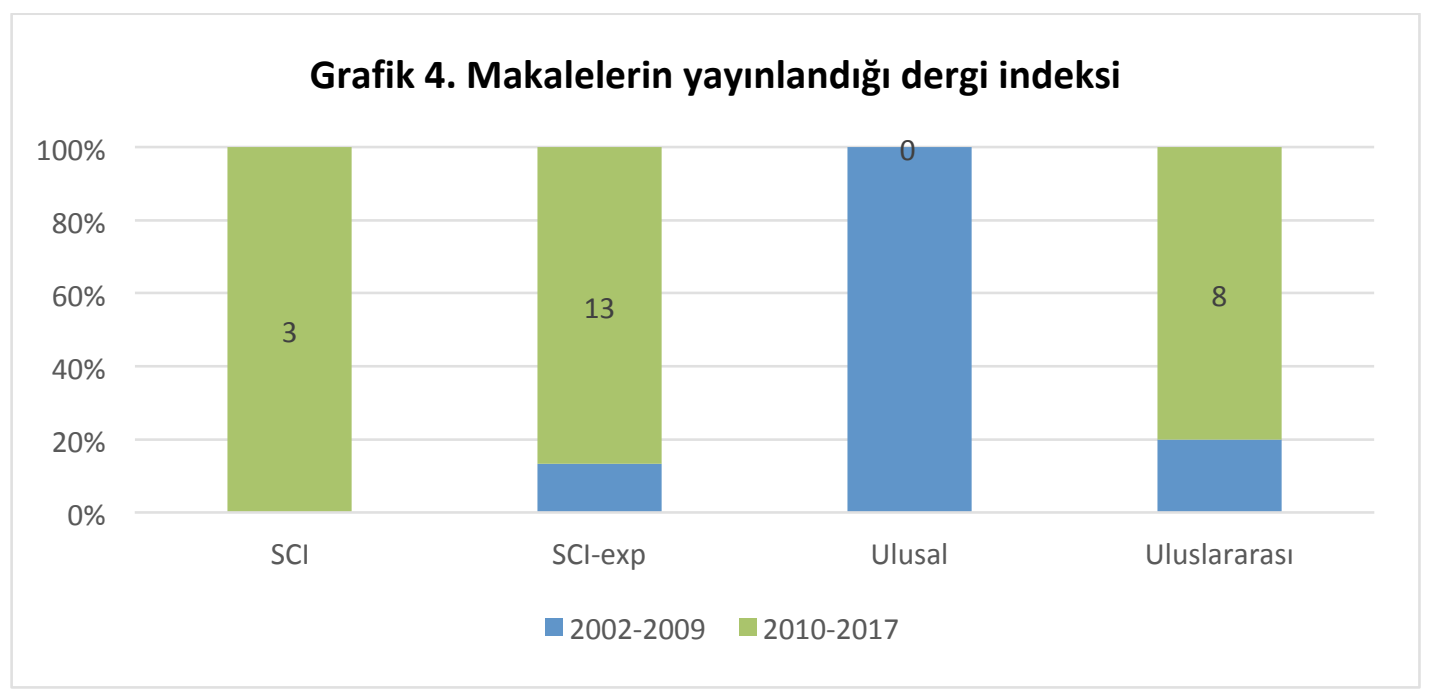

SCI: Science Citation Index, SCI-exp: Science Citation Index expanded.

\section{TARTIŞMA}

2002-2017 yılları arasında tamamlanan tezlerde en sik egzersiz ve spor fizyolojisi, spor yaralanmaları ve sportif rehabilitasyon konularında, ardından kronik hastalıklar ve egzersiz ile spor kardiyolojisi kapsamında çalışmalar yürütülmüştür. Müfredatta yer alan; yaşlılık ve spor, kadın ve spor, engelliler ve spor, takım doktorluğu, spor hekimliğindeki acil durumlar ve organ nakilleri kapsamındaki çalışmaların henüz tez konusu olarak seçilmediği tespit edilmiștir. Tamamlanan tezlerin makaleye dönüştürülme oranı \%48.3 olup, özellikle son yıllardaki yayınların dilinin İngilizce olması uluslararası literatüre katkı açısından önemlidir. Ancak hem çalışma kapsamı çeşitliliğinin hem de tezlerin makaleye dönüştürülme oranlarının arttırılması gerekmektedir.
Spor hekimliği 'Toplumdaki bireylerin sağlığının korunması ve geliştirilmesi için fiziksel aktiviteye katılımın arttırılması, her cinsten ve yaștan sağlıklı veya kronik hastalığı olan bireylerin, hangi düzeyde olursa olsun spora katılım öncesi sağlık değerlendirmelerinin yapılması, spora ve fiziksel aktiviteye katılımla ilgili program yapılması ve egzersiz reçetesi uygulamaları, katılımcıların karşılaştıkları yaralanmaların ve sağlık sorunlarının önlenmesi, tanı, tedavi ve rehabilitasyonu, sporcu performansının tıbbi yönlerinin değerlendirilmesi ve dopingle mücadele edilmesi konularında teorik ve uygulamalı çalışmalar yapan klinik bir uzmanlık dalıdır' (8). Tanımda da net bir şekilde ifade edildiği gibi bu alanda görevli kişiler sadece sporcuların değil toplum sağlığının da geliștirilmesinde kilit rol almaktadır. Fakat sadece hekimlerin değil toplumun da bu hizmetlerin spor hekimliği uzman- 
ları tarafından verildiğini biliyor olması gerekir. Hekim-hekim, hekim-sporcu/hasta arasındaki karşılıklı iletişimin etkinliği spor hekimliğinde ihmal edilen alanların azaltılması/giderilmesi ve yapılan çalışmaların yayına dönüştürülebilmesi ile sağlanabilir.

Düzenli egzersizin kardiyovasküler hastalık, tromboembolik inme, hipertansiyon, tip 2 diyabet, osteoporoz, obezite, kolon kanseri, meme kanseri, anksiyete, depresyon, demans gibi birçok hastalığın riskini azalttığı, bunun yanı sıra terapötik etkinliğinin bulunduğu da bilinmektedir (9). Yaşlı nüfusun gün geçtikçe artıyor olması geriyatri biliminde kronik hastalıkları önleyici, tedavi edici, yaşlıların bağımsızlı̆̆ını ve fonksiyonlarını arttırıcı egzersiz uygulamalarının yapılmasını gerekli kılmaktadır. Egzersizlerin doğru planlanması ve bu yaş grubuna özgü sorunların etkili bir şekilde çözülebilmesi, spor hekimliği uzmanlarının bu alanda da görev almalarına bağlıdır (10).

Kadınların spora katılımlarının artması, yaralanmaların spora özgü olmasının yanı sıra cinsiyete bağlı olarak da ortaya çıkabildiğini göstermiştir. Birçok epidemiyolojik çalışma, kadınların yaralanma mekanizmalarının, yaralanmadan korunma ve tedavi stratejilerinin farklılık gösterdiğini bildirmektedir (11). Diğer taraftan kadın sporcu üçlemesi, gebelik ve menopoz süreçleri de dikkat çekici özelliklere sahiptir (12). Bu grupta karşılaşılabilecek sorunlar ve bu sorunların çözüm yolları yapılacak araştırmalarla netlik kazanabilecektir. Özellikle ülkemizdeki durumun açıklığa kavuşması araştırmacı hekimlerin çalışmalarına bağlıdır.

Engelli bireylerin spora katılımı kültürel ve sosyal faktörler sebebiyle göz ardı edilmektedir. Bilimsel kanitlar ise engelli bireylerin spora katılmalarının, daha az tıbbi komplikasyon yaşamalarına ve daha az hastane başvurusu yapmalarını sağladığını göstermektedir. Bunun yanında engelli bir bireyin spor yapması psikososyal iyilik halini de arttırmaktadır (12). Bu özellikli grubun birincil koruma, tanı, tedavi ihtiyaçlarının giderilmesi için spor hekimliği uzmanlarınca yürütülecek bilimsel çalışmalara ihtiyaç vardır.
Spor hekimliği alanında sık karşılaşılan acil durumları yönetebilmek ve takım doktorluğu yapmak klasik hekimlik uygulamalarından farklılıklar göstermektedir. 'Takımın arkasındaki takım' olarak başarılı olabilmek bilgi, beceri ve yüksek iletişim kabiliyeti gerektirmektedir $(12,13)$. Diğer taraftan takım doktorunun tıbbi etik yaklaşımını koruyarak kriz dönemlerini yönetmesi de beklenmektedir (14). Bu konu kapsamında elde edilen bilgi ve tecrübelerin literatürümüze kazandırılması bu alandaki eksikliği gidermeye katkı sağlayacaktır.

Yüksek öğretim kurumları gibi saygın kurumlar tarafından üretilen bilginin açık erişim ile ulaşılabiliyor olması bilimsel iletişimin artmasını sağlamaktadır (15). Ülkemizde kurulan dijital ulusal tez arşivi, bilginin serbest erişimine ve sınırsız kullanımına örnektir (15). Fakat 2002-2017 yılları arasında spor hekimliği uzmanlık tezini tamamlamış olduğu bilinen en az 3 spor hekimliği uzmanının tez dosyasına erişilememiş olması çalışmanın kısıtlılıklarındandır. Ayrıca, bazı tezler sadece basılı yayın yapan dergilerde yayımlanmış ise bu çalışmalara dijital tarama ile ulaşılamamış ve makale olarak yayımlanmadığı çıkarımı yapılmış olabilir. Özellikle son yıllara ait çalışmalar dergilerde yayın için kabul edilmiş ancak henüz açık erişime sunulmamış olabilir. Ayrıca, tezin çalışma kapsamının tek kişi tarafından belirlenmiş olması, ikinci bir uzman tarafindan tematik analiz yapılıp uzmanlar arasındaki iç uyuma bakılmamış olması bu çalışmanın diğer bir kısıtlılığıdır.

\section{SONUÇ}

Spor hekimliği, ülkemizde henüz gelişimini sürdüren bir uzmanlık alanıdır. Görev tanımı içerisinde yer almasına rağmen ihmal edilen alanlar bulunmaktadır. Ulusal literatürdeki eksikliklerin giderilmesi ve uluslararası literatüre yapılacak katkıların artması beklenmektedir.

\section{KAYNAKLAR}

1. Daneshvar M, Kazemi A, Paslarzadeh M, et al. A content analysis of theses of Hormozgan University of medical sciences in the period from 2006 To 2013. Research Journal of Pharmaceutical, Biological and Chemical Sciences. 2016;7(1):537-40. 
2. Lindahl J, Stenling A, Lindwall $M$, et al. Trends and knowledge base in sport and exercise psychology research: a bibliometric review study. International Review of Sport and Exercise Psychology (IRSEP). 2015;8(1):71-94.

3. Gurbuz Y, Sugun TS, Ozaksar K. A bibliometric analysis of orthopedic publications originating from Turkey. Acta Orthop Traumatol Turc. 2015;49(1):57-66.

4. Malik M. Bibliometric study of political science Ph. D. thesis, Vikram University, Ujjain (MP) (2009-2012). International Journal of Digital Library Services. 2016;6:128-38.

5. Ullah S, Jan SU, Jan T, et al. Journal of the College of Physicians and Surgeons of Pakistan: Five years bibliometric analysis. J Coll Physicians Surg Pak. 2016;26(11):920-3.

6. Machan K, Portero FS. Doctoral theses in diagnostic imaging: a study of Spanish production between 1976 and 2011. Radiologia. 2018;60(5):394-403.

7. Fares MY, Fares J, Baydoun H, et al. Sport and exercise medicine research activity in the Arab world: a 15year bibliometric analysis. BMJ Open Sport Exerc Med. 2017;3(1):e000292.

8. Tipta uzmanlık kurulu müfredat oluşturma ve standart belirleme sistemi, spor hekimliği uzmanlık eğitimi çekirdek müfredatı versiyon 2.2. Erişim adresi: https://tuk.saglik.gov.tr/TR,31295/spor-

hekimligi.html

9. Nelson ME, Rejeski WJ, Blair SN, et al. Physical activity and public health in older adults: recommendation from the American College of Sports Medicine and the American Heart Association. Circulation. 2007;116(9):1094-105.

10. Runge M, Rehfeld G, Resnicek E. Geriatric patients in balance training and exercise. Am J Orth and Rhe. 2018; 1(1):1-3.

11. Sallis RE, Jones K, Sunshine S, et al. Comparing sports injuries in men and women. Int J Sports Med. 2001; 22: 420-3.

12. Whyte G, Loosemore M, Williams C, editors. $A B C$ of sports and exercise medicine. John Wiley \& Sons; 2015.

13. Malcolm D. Sport, Medicine and Health: The medicalization of sport?. Routledge;2016.

14. Malcolm D. Confidentiality in sports medicine. Clin Sports Med. 2016;35(2):205-15.

15. Polat C. Bilimsel bilgiye açık erişim ve kurumsal açık erişim arşivleri. Atatürk Üniversitesi Fen Edebiyat Fakültesi Sosyal Bilimler Dergisi. 2006;6(37):53-80. 